\title{
Fear of Intimacy in Rabih Alameddine's I, The Divine
}

\section{Ikram LECHEHEB}

\begin{abstract}
The paper examines how the Lebanese American novelist Rabih Alameddine in I, The Divine (2002) shows the psychology of hybrid subject in Diaspora. Through creating a fictional space, the author sheds light on how Sarah suffers from fear of intimacy due to a combination of past traumatic experiences: The Lebanese Civil War, the rape scene, separation from her mother. Through a close reading of Alameddine's novel, the study does not only stress how fear of abandonment, fear of betrayal, and fear of low self-esteem intertwine to form a fear of intimacy in Sarah's emotional relations, but it also highlights how the protagonist unconsciously avoids attachment as a defense mechanism employing Freud's ideas.
\end{abstract}

Keywords - Rabih Alameddine; I, The Divine; Sigmund Freud; Psychology; Trauma; Fear of Intimacy.

Even though intimacy has not only a vital importance in daily life, but it also has a long history of its study, it continues to be a complex, broad, and multifaceted concept that has referred to in different disciplines as Literature. As an illustration, Arab writers in Diaspora stress Arabs' experiences with a particular focus on social and psychological aspects. To put differently, Arab authors go deeper in analyzing the complexities of life and the psychology of Arabs in diaspora. In this respect, the current study delves into examining the concept of fear of intimacy through a close reading of Rabih Alameddine's $I$, The Divine. For the sake of conducting the study, the paper offers a sketch of its theoretical underpinnings, defines key concepts used herein, and outlines the main aspects of dynamics of the relationship between fears of (abandonment, betrayal, and low self- esteem), and a fear of intimacy as core issues for Sarah, a major character, in Alameddine's novel. Importantly, the character's analysis is shown in the light of the wealth of theorization in the numerous psychoanalytic works. In order to validate the suggestion that Alameddine's I, The Divine highlights fear of intimacy as a main problem for Sarah, the study does not only incorporate a set of critical and theoretical views, but it also employs exploratory, investigative methods. Additionally, textual and analytical methods are integral to the discussion especially that they are major tools of getting deeper insight into how fear of intimacy is projected in the novel.

Before venturing into further details, few words have to be revealed concerning fear of intimacy from a psychological angle. It is not surprising that Sigmund Freud's works chart the psychoanalytic analysis of the defense process or what he later on refers to ego's defense mechanisms. These latter are systematic processes and psychological strategies that are unconsciously used to protect the person from anxieties and certain fears as the fear of intimacy. Freud points out, "We defend ourselves from unwanted information by air- brushing it out of existence, rendering it inaccessible to our conscious mind" (IX). In his Beyond The Pleasure Principle (1920), Freud accentuates that the ego affords protection against undesirable experiences whenever it is alerted. It is worth noting that Freud not only classifies fear as a part of defense process, but he also declares that the ego is the locus of fear asserting, "Fear consists in a reaction to a particular danger situation; the ego saves itself from this fear by taking action to withdraw from the situation or avoid it altogether" (197). In A General Introduction to Psychoanalysis (1920), there is a chapter entitled "Fear and Anxiety" in which Freud deals with fear and its connection with narcissism, anxiety, and how they affect intimacy or what Freud refers to as a fear of intimacy. Additionally, Freud indirectly explains that fear of intimacy results from the accumulated undesirable emotions including avoidance, abandonment, and betrayal.

Freud's reference to defense mechanisms becomes the exemplary modal and a useful tool par excellence for recent studies dealing with defense mechanisms. It is useful, then, to consider other theorists' works in which they address the same concept drawing on Freud's touch in the field. In his oeuvres, Lois Tyson (2006) highlights that defense mechanisms involve various forms including repression, selective perception, selective memory, denial, avoidance, and displacement.(6) The present study sheds light particularly on fears of abandonment, betrayal, low self-esteem, and insecure sense of self that lead to fear of intimacy. Additionally, in their "Development and Validation of a Fear of Intimacy Scale," (1991) Descutner and Thelen define the above- mentioned concept as, "The inhibited capacity of an individual, because of anxiety to 
exchange thoughts and feelings of personal significance with another individual who is highly valued" (219). From the above definition, one argues that the avoidance of intimate relationships is a coping mechanism assisting individuals in managing the anxieties. In Childhood and Society (1963), Eric Erikson identifies and develops eight stages in his theory of human development. In the sixth stage, "intimacy versus isolation," Erikson highlights that the lack, fear, and avoidance of intimacy may result in isolation. As another existing literature on fear of intimacy, Firestone and Catlett argue in Fear of Intimacy(1999)that the concept is seen as a sort of defensive mechanism protecting the individual from harm and pain by retreating and taking a defensive posture. In addition to the theoretical work of Erikson and others, studies have also shown support for the relationship between intimacy and psychological well-being. In this respect, in Fear of Intimacy in Females: an Investigation of Fear of Intimacy, Scale Scores in Relation to Gender Roles (2009), Leslie Rautzhar Murray concludes the study arguing,

Insufficient intimacy has been correlated with depression, loneliness, isolation, and physical health problems... fear of intimacy has also been shown to have negative impacts on recovery from depression and should be considered to be a risk factor for emotional difficulties... individuals who experience fear of intimacy are less likely to perceive and utilize social support. (27)

From the above- mentioned quote, one says that fear of intimacy intertwines with a combination of aspects including loneliness and isolation. These latter are risk factors that force the individual to unconsciously avoid attachment and emotional relations.

In the discussion of the Arab literature in Diaspora, Rabih Alameddine's literary works are frequently noted. He is a Lebanese American author whose works not only examine Arabs' experiences in Diaspora, but also show his literary touch to the field through adding a transnational diasporic character. In this respect, Carol FaddaConrey(2009) argues, "Rabih updates and revises traditional definitions and portrayal of Arab and Lebanese subject in USA... The author breaks the notion of home, national belonging, and cultural identities through [using] Sarah as an epitome of a transnational diasporic subject" (178). Additionally, Alameddine's fiction combines historical particularities with psychoanalytic universals in the individual's diasporic life. In this sense, it is the intention of this paper to highlight the manifestation of fear of intimacy in Alameddine's I, The Divine. The latter revolves around the protagonist, Sarah, who is preoccupied with converting traumatic memory into narrative memory. The novel involves the rhythms, processes, and uncertainties of trauma that lead Sarah to suffer from a large number of psychological upsets and disorders. While keeping in mind the Freudian concept of a psychoanalytic study of human behavior, Tyson argues that human beings encounter with various painful experiences including excessive emotions, fears, guilt and conflicts unconsciously which we do not want to get to be overwhelmed. Tyson continues that these painful experiences are projected through strong defense mechanisms.(16) Due to a combination of fears of betrayal, abandonment, and low self- esteem, Sarah, therefore, experiences fear of intimacy as a defensive posture.

The exploratory structure of the study proposes a journey into reading $I$, The Divine from the lens of psychoanalysis highlighting how Sarah's fear of intimacy is shown. It is worth noting that Sarah's fear of intimacy stem from several past traumatic experiences. To begin with, Sarah's connection with her grandfather is the first risk factor for her fear. At the day of her birth, the grandfather named Sarah after "the divine" French theatrical actress, Sarah Bernhardt. Sarah Additionally sees her grandfather as a modal person. As time runs, Hammoud nourishes Sarah with notions of uniqueness and narcissism. The latter can be in a way or another connected with fear of intimacy because narcissism is a personality trait, which is associated with the lack of intimacy in interpersonal relationships. Narcissistic persons consider themselves different, or unique, as well superior to or better than others and have difficulties in being easily attached to others. In Beyond the Pleasure Principle, Freud refers to the narcissist person as "The narcissist exudes charisma, in the secular rather than the sacred sense. He needs nothing and no one but himself. The narcissist sends off a glow of sheer inviolability. Nothing gets to him. Nothing daunts him. His being is unified, coherent and composed" (XV). The narcissist person suffers from isolation and a lack of attachment with others. On this basis, in "Who is Sensitive to Rejection? The Role of Attachment, Narcissism and the Fear of Intimacy," (2011) Ricky Finzi Dottan; DovHar, Euen; and Galit Ray point out, "Insecure attachment patterns are associated with pathological forms of narcissism." (193)

As time runs, Sarah discovers that Hammoud had not only lied about having met the divine, but he also has other vices: religious bigotry, xenophobia, and misogyny. In this vein, she confesses, "It took me years and almost three hundred pages of aborted narrative attempts to accept 
the truth." (40) In one of her conversations with her mother, Sarah acknowledges that

These days, I also hear my mother cursing him, calling him all kinds of names. She has been dead for some years now, but I hear she curse the son of bitch for the things he put her through 'he worked and worked until your father was forced to divorce me' my mother cursed him till the day she died. 'He was evil, evil incarnate. Everybody thought he was the nicest man, but the things he did, the things he said.' 283

From the above two quotations, one highlights that Sarah feels a sense of betrayal from her grandfather. With accumulation, and combination with other fears, Sarah unconsciously works her ego mechanisms in avoiding intimate relationships due to her narcissistic character and the feeling of betrayal from her grandfather. Freud points out,

"Psychoanalysts were then struck in the course of their observations by the fact that individual elements of narcissistic behavior are encountered in many people suffering from other disorders" (3) especially through the projection of fear of intimacy in the individuals' relations with others.

What is noteworthy here is that fear of intimacy also originates from the emotional neglect; that is, it is connected with children whose parents are not emotionally available. In Sarah's case, during her childhood, Sarah sees the father as a center of the universe asserting, "I was his favorite daughter, his Cordelia. He always considered my uniqueness enchanting." (35) She continues, "When I was growing up, my father was the center of my universe. I considered him the handsomest man in the world, tall, dark hair, and eyes, with the ubiquitous Lebanese mustache"(126). Chiefly, the whole family noticed Sarah's connection with Mustafa. In one of her letters, Lamia confesses, "My father loves her and always Sarah this and Sarah that thing and she is graduate from Barnard and she is the smart one and she is the joy of his heart and she is the apple of his eye and she is the flower of every four seasons." (152-153)Through the process of reading, one notices that Sarah feels detached from the father especially after divorcing her mother. In this vein, the protagonist asserts, "My father had divorced my mother, sent her packing back to America, and married a younger Lebanese woman. I saw my stepmother as a family intruder and spent most of my childhood trying to make her life miserable." (11) In another incident, Sarah mentions, "I grew up angry with my father because he destroyed the fairy tale... I did not forgive my father and his treatment to my mother." (46;49) Sarah adds, "My stepmother was furious... She turned my father against me... My father was the one who beat me for that, with the belt of course, in the bathroom" (35) Sarah concludes by referring to the family's curse of loneliness and disharmony," Our family never sang, never came together in joy... We had no family outings. Our family did not believe it could fly." (134- 135) In this context, one should consider that Sarah's detachment from her parents not only leads her to be psychologically distressed, not being so attached to others, but also leads her ego to be alerted.

In the wake of discussing how fear of intimacy is projected in Sarah's connections with others, it is useful to highlight that Sarah's fear of intimacy begins in unconscious manner especiallyafter being detached from [grandfather, father, and mother]leading her to emotional distraction in the form of drama of dysfunctional love.On this basis, in Fear of Intimacy in Romantic Relationships during Emerging Adulthood: The Influence of Past Parenting and Separation- Individuation (2011),Elizabeth Lioyd Marriannementions, " Past experience in the parentchild relationship has been found to influence both the capacity to form romantic relationships and separation individuation." (1)

Psychologically speaking, the person who is emotionally detached from someone again needs to have someone else to be attached. As one of the chief aspects of human behavior investigated in Alameddine's novel is the romantic relationship in the form of fear of intimacy. Sarah has not a complete ability to genuinely share her true self with men. Sarah now has the opportunity to forget the pain of separation from Hammoud, Mustafa, and Janet through her love relationship with Fadi. The latteris seen as a sort of relief from previous detachments. Sarah refers to Fadi as her soul mate who "changed my life forever... the boy who turned my world upside down" (5-6). In this context, one considers that Sarah's attachment to that boy isactually a repression of psychological wounds that she received in the form of separation from her parents. It is, therefore, a psychological need for her to quit her mental separation from her parents.

It is worth exploring that Sarah's fear of intimacy is not only resulted from her detachment from her parents, it is also caused by The Lebanese Civil War. In other words, war trauma was enough to get her reject emotional relationships. In this vein, Syrine C. Hout(2008) argues, "War engenders a collective trauma whose psychological effects may continue to wrap up the lives of the survivors long after the guns fallen silent." (3) In the same path, Sarah mentions, "Beirut will remain haunted if it simply 
cleans up its façade." (112) In seeking to glean how fear of intimacy appears in Sarah's individual experiences, one has to shed light on the rape scene as another core factor that highly affects Sarah's emotions and connection with men. Due to that incident, Sarah suffers from the posttraumatic stress disorder in a way that in both dreams and reality she repetitively wants to "rub herself raw and get out of her skin" (122). In that sense, Hout asserts, "What triggers this traumatic memory [The rape scene]is the belated- and for this purpose necessary intense emotional crisis that Sarah was in twenty years later." (5)Whatever psychological crises Sarah suffered in her past life, they are, in her unconscious side, proper ways to have the emotional insulation one needs to avoid intimacy with others. This sort of avoidance is manifested in her first marriage.

In her marriage, Sarah was attached to Omar as a psychological refuge from her detachment from parents, and Fadi. The protagonist narrates that her connection with Omar begins to change in New York especially after he decides to go back to Lebanon, "Omar may have begun to nag at times, but his behavior changed a little. My behavior did not change either, but my feelings did." (52) She continues, "In June, my husband and my son left me... leaving me completely alone in an unforgiving city, without family or friends." (54; 83)At that time, Sarah's worries are double mainly because the husband does not respond according to the protagonist's desire. In a study conducted on the relationship between the fear of intimacy and marital satisfaction, DityBrunn (2001)argues, "Central to the fear of intimacy is the theory that human beings are driven by the two major emotions of fear and love. Further, these two emotions can co- exist and can build upon each other." (25) From the above quotation, one notices that Sarah's previous fears of betrayal and abandonment merge with her love for Omar forcing her to be under an emotional drive. The latter leads her towards distraction, loneliness, and other accumulations of her fears.

As a way to relieve her previous psychological pains, the protagonist engages with the graduate engineering student, Joe, and has an emotional relation giving a justification that, "But that is not why I am having an affair. I want to be with someone. I am really lonely." (132)Psychologically speaking, one argues that the fear that arouses in Sarah's mind is resulted from a fear of separation from Omar; that is, the psychological wounds overcome her mind and she tries to avoid other emotional relations. Consciously, she has settled the issue that it is no matter but it has actually become now the core issue for her unconsciously. For that reason, she directly goes to have an emotional relation with Joe.
In applying the Freudian psychoanalytic analysis on the character of Sarah, it is explicit that the repressed fears are revealed especially in her relation with David. In other words, the fear of intimacy can resulted from the fear of being engulfed; that is, the fear of losing one's individuality. Elizabeth ends up the study arguing that separation- individuation is linked to fear of intimacy in a way it may influence the development of capacity for intimacy via fear of intimacy. In Sarah's connection with David, she declares,

I met David at a low point in my life and he gave me direction, became both my compass and my anchor. I was failing and he gave me focus... He was instrumental in furthering my artistic career. He waved at me when he came in, walked around the gallery, and left without saying good-bye. For a long time after that I had to hear about how I had ignored him.(103-104; 106)

From the quote, one says that Sarah is psychologically in doubtful condition and her fear of intimacy is clearly shown. Sarah has to get rid of these undesirable feelings through the ego's defense mechanisms. The latter function in avoiding dangers and protect the self from painful feelings of anxiety, inadequacy, and mental sufferings. It is worth noting that Sarah's ego is overwhelmed with the idea that she will no more be emotionally attached with David and will rather care of herself and her creative art. Dityargues in Intimacy and Marital Dissatisfaction, "When individuals are faced with the fear of intimacy, stemming from an awareness of the risks that are involved in being intimate with another, they may impair the relationship by avoiding taking the risks." (26)

It is worth highlighting that fear of intimacy can play out in a number of different ways in any type of relationship, whether romantic, platonic, or familial. In severe cases, fear of intimacy can lead to the extreme when it comes to physical contact. In other words, the person who suffers from the above- mentioned psychological problem might avoid corporeal attachment. This notion is projected in Sarah's connection with David. Sarah's decision to disintegrate in any further relation is the result of her digressive life with her parents, and men. Additionally, Sarah's unconscious decision plays a key role as an unconscious move for gaining a treasure that keeps her safe from the psychological devastation. By the end of the novel, Sarah becomes a visual artist who reveals in a moment of self- discovery and epiphany that she has not only to overcome her fears, but also to configure and re- configure her identity declaring, "I had tried to write 
my memoir by telling an imaginary reader to listen to my story. Come learn about me, I said. I have a great story to tell you because I have led an interesting life." (308)

Through a close reading of Alameddine's I, The Divine, one concludes by asserting that Alameddine's novel is a predicament of psychological processes particularly fear of intimacy. Various biographical episodes in Sarah's life show her suffering from fear of intimacy including a combination of past traumatic experiences: the Lebanese Civil War, the rape scene, and separation from her mother to the extent she is unable to develop a satisfying relationship with men. In employing Freudian psychoanalytic concepts of fears, defenses, and fear of intimacy as core issues, the study shows that Sarahun consciously experienced fears of betrayal, abandonment. Due to these fears, the protagonist not only tries to keep herself at emotional distance from men as a part of ego defenses, but she also survives the effects of post-traumatic stress disorder and a combination of fears through working out her ego defenses and being a creative artist.

\section{REFERENCES}

[1] Alameddine, Rabih. I, the Divine: A Novel in First Chapters. New York: Norton and Company, 2002

[2] Brunn, Dity.The Relationship between Fear of Intimacy and Marital Dissatisfaction.Diss.USA, 2001.

[3] Conrey, CaralFadda. "Transnational Diaspora and the Search for home in RabihAlmeddine's I, the Divine: a novel in First Chapters." In Arab Voices in Diaspora: Critical Perspectives on Anglophone Arab Literature. 2009. 143- 163.

[4] Descutner, C.J., and Thelen,M.H. "Development and Validation of a Fear of Intimacy Scale. Psychological Assessment."AJournal of Consulting of Clinicaal Psychology.3(2), (1991) 218- 225.

[5] Dottan, Ricky Finzi; Euen, DovHar; and RazGalit." Who is Sensitive to Rejection? The Role of Attachment, Narcissism and the Fear of Intimacy."In Interpersonal Acceptance and Rejection.2011, 183-197.

[6] Erikson, E.H. Childhood and Society ( $2^{\text {nd }}$ Ed) New York: Norton Press, 1963

[7] Firestone, R.W. and Catlett, J. Fear of Intimacy. Washington, DC: American Psychological Association, 1999.

[8] Freud, Sigmund. The Ego and Mechanism of Defense. London: Hogarth Press and Institute of Psycho- Analysis, 1937

[9]__ Beyond the Pleasure Principle.Trans. James Stracley. New York: Norton, 1961

[10] __ A General Introduction to Psychoanalysis. Trans. New York: Boni and Liveright, 1920.

[11] Hout, Syrine C. "The Tears of Trauma: Memories of Home, War, and exile in Alameddine, Rabih. I, the Divine: A
Novel in First Chapters." World Literature Today.82/ 5.2008, 58- 62 .

[12] Lioyd, Marrianne Elizabeth. Intimacy in Romantic Relationships during Emerging Adulthood: the Influence of Past Parenting and Separation Individuation. Diss.Victoria University, 2011.

[13] Murray, Leslie Rautzhar. Fear of Intimacy in Females: an Investigation of Fear of Intimacy, Scale Scores in Relation to Gender Roles. Diss. Widener University. 2009

[14] Tyson, L. Critical Theory today: a User Friendly Guide. New York: Routledge. 2006 